
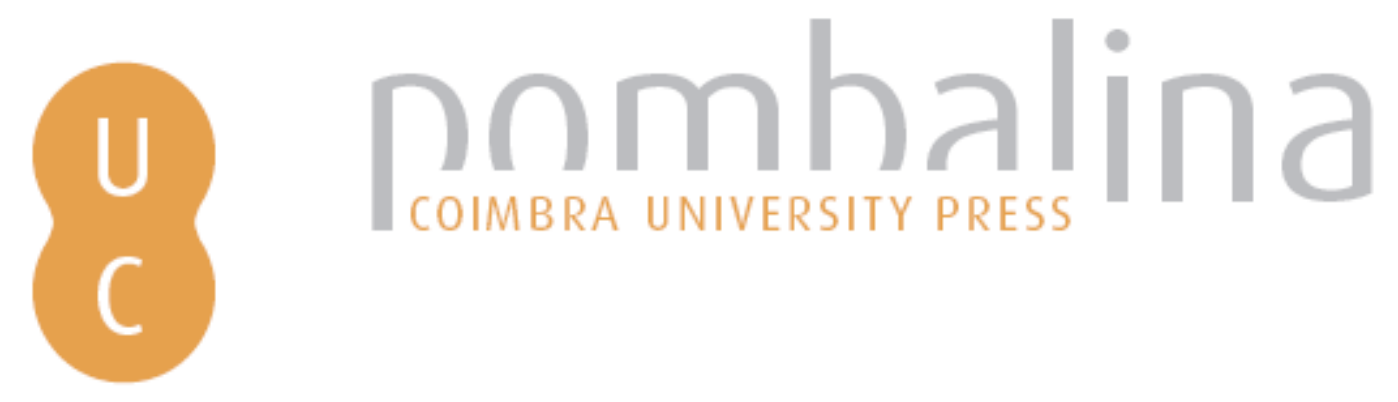

\title{
Tendências de evolução regional dos grandes incêndios florestais (100 Ha) em Portugal Continental, nas últimas três décadas
}

\author{
Autor(es): $\quad$ Leite, Flora Ferreira; Gonçalves, António Bento; Lourenço, Luciano; \\ Nunes, Adélia; Vieira, António \\ Publicado por: Imprensa da Universidade de Coimbra; RISCOS - Associação \\ Portuguesa de Riscos, Prevenção e Segurança
}

URL

persistente:

URI:http://hdl.handle.net/10316.2/34928

DOI:

DOI:http://dx.doi.org/10.14195/978-989-96253-3-4_128

Accessed : $\quad$ 26-Apr-2023 16:33:18

A navegação consulta e descarregamento dos títulos inseridos nas Bibliotecas Digitais UC Digitalis, UC Pombalina e UC Impactum, pressupõem a aceitação plena e sem reservas dos Termos e Condições de Uso destas Bibliotecas Digitais, disponíveis em https://digitalis.uc.pt/pt-pt/termos.

Conforme exposto nos referidos Termos e Condições de Uso, o descarregamento de títulos de acesso restrito requer uma licença válida de autorização devendo o utilizador aceder ao(s) documento(s) a partir de um endereço de IP da instituição detentora da supramencionada licença.

Ao utilizador é apenas permitido o descarregamento para uso pessoal, pelo que o emprego do(s) título(s) descarregado(s) para outro fim, designadamente comercial, carece de autorização do respetivo autor ou editor da obra.

Na medida em que todas as obras da UC Digitalis se encontram protegidas pelo Código do Direito de Autor e Direitos Conexos e demais legislação aplicável, toda a cópia, parcial ou total, deste documento, nos casos em que é legalmente admitida, deverá conter ou fazer-se acompanhar por este aviso.

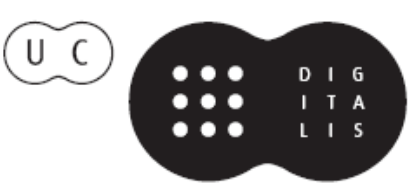



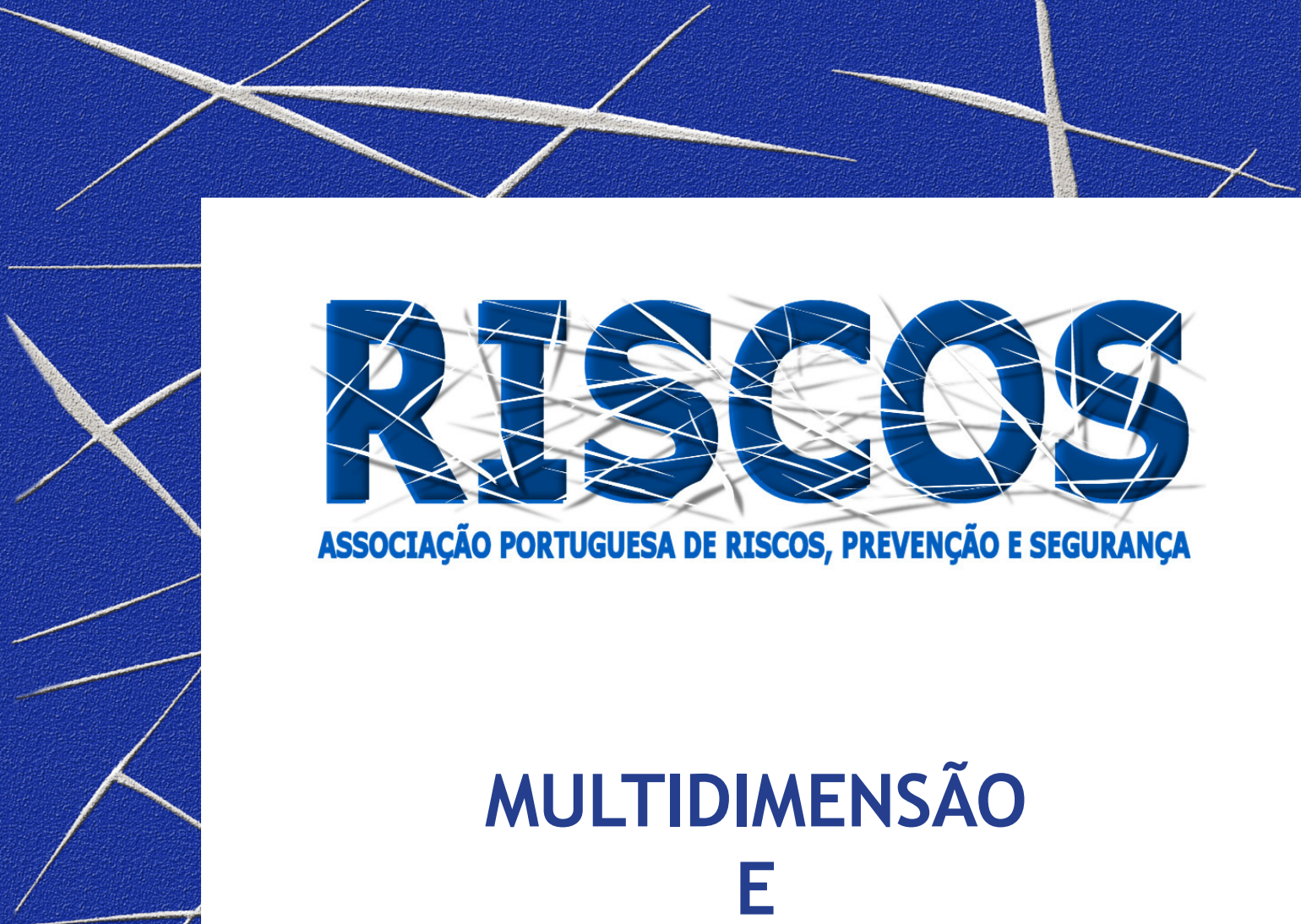

ASSOCIAÇÃO PORTUGUESA DE RISCOS, PREVENCCÃO E SEGURANÇA

MULTIDIMENSÃO

E
TERRITÓRIOS DE RISCO

III Congresso Internacional

I Simpósio Ibero-Americano

VIII Encontro Nacional de Riscos

Guimarães

2014 


\title{
TENDÊNCIAS DE EVOLUCCÃO REGIONAL DOS GRANDES INCÊNDIOS FLORESTAIIS ( $(100$ HA) EM PORTUGAL CONTINENTAL, NAS ÚLTIMAS TRÊS DÉCADAS
}

\author{
Flora Ferreira Leite \\ Bolseira FCT, CEGOT, Universidade do Minho \\ floraferreiraleite@gmail.com \\ António Bento Gonçalves \\ Departamento de Geografia e CEGOT, Universidade do Minho \\ bento@geografia.uminho.pt \\ Luciano Lourenço \\ Departamento de Geografia e CEGOT, Faculdade de Letras da Universidade de Coimbra \\ luciano@uc.pt \\ Adélia Nunes \\ Departamento de Geografia e CEGOT, Faculdade de Letras da Universidade de Coimbra \\ adelia.nunes@ci.uc.pt \\ António Vieira \\ Departamento de Geografia e CEGOT, Universidade do Minho \\ vieira@geografia.uminho.pt
}

\begin{abstract}
RESUMO
Temos assistido, ao longo dos últimos anos, a uma nova realidade em Portugal, no que respeita aos grandes incêndios florestais ( $\geq 100 \mathrm{ha}$ ).

$\mathrm{Na}$ última década registaram-se os incêndios florestais de maior dimensão no território português (FERREIRALEITE et al., no prelo), apesar de não se ter registado a maior percentagem de grandes incêndios florestais $(0,7)$, mas verificou-se maior área ardida (79\%), o que significa que, em média, cada grande incêndio, nesta década, queimou mais do que os das décadas anteriores (672 ha). Isto resultou, por um lado, da redução do número de grandes incêndios florestais ao longo dos anos e, por outro, do aumento da área individual percorrida por cada um dos grandes incêndios.

Quando se analisa a distribuição espacial destes incêndios verifica-se que há distritos especialmente suscetíveis à sua ocorrência e desenvolvimento. É neste sentido que nos propomos analisar as tendências de evolução regional, no período de 1981 a 2013.
\end{abstract}

Palavras-chave: Portugal, grandes incêndios florestais, tendências, evolução.

\section{Introdução}

Quando se analisa a distribuição espacial dos incêndios em Portugal, verifica-se que há distritos especialmente suscetíveis à sua deflagração e outros mais favoráveis à propagação das chamas (NunEs, 2012; NunEs et al., 2013). De qualquer forma, são conhecidas as dicotomias norte/centro vs sul e litoral vs interior, tanto no que se refere ao número de ocorrências como à área ardida (LOURENço et al., 2012).

No caso particular das áreas ardidas, a propagação do fogo está sobretudo dependente de uma série de fatores físico-geográficos, como sejam as condições climático-meteorológicas e/ou a topografia (Lourenço, 1988, 1991; Lourenço e Bento-Gonçalves, 1990) e de fatores de natureza cultural e de índole socioeconómica, com consequências importantes ao nível do (des) ordenamento do território (Bento-Gonçalves, 2006; Bento-Gonçalves et al., 2000; Moreira et al.,2011), entre outros.

Ao longo das últimas décadas, a existência e a manutenção destes cenários proporcionou a propagação dos incêndios, e, assim sendo, a existência de GIF no nosso país. 


\section{Os grandes incêndios florestais em Portugal (1981-2013)}

Com base nas estatísticas dos incêndios disponibilizadas online pelo ICNF, observa-se um cenário de aumento efetivo do número de GIF ao longo das últimas 3 décadas. Mas, se o aumento do número de GIF foi significativo, no que respeita à área ardida o acréscimo foi ainda maior (de 563950 ha para mais do dobro, 1164748 ha), o que se refletiu no aumento da percentagem da área consumida pelos grandes incêndios e, por conseguinte, no acréscimo do valor da área média por GIF (FerReIRA-LeITE et al., no prelo).

Assim, em termos gerais, nos últimos 30 anos, os GIF representaram uma pequena fração do número total das ocorrências registadas em Portugal $(0,8 \%)$ mas, em contrapartida, foram responsáveis por 72,5\% da área ardida (FerReIRA-Leite et al., 2013).

\section{Tendências de evolução anual da área ardida em grandes incêndios, por distrito, entre 1981 e 2013}

Comprovada a importância das áreas queimadas por GIF em Portugal, pretende-se analisar agora a sua distribuição espacial e detetar as tendências de evolução, no período de 1981 a 2013, na percentagem de áreas ardidas por GIF, relativamente à superficie de espaços silvestres, a nivel distrital. Para o efeito, selecionou-se a linha de tendência (polinomial de 3 ordens) que melhor se ajustava à respetiva distribuição espácio-temporal.

Assim, através da configuração das linhas de tendência definidas para os distritos de Beja, Castelo Branco, Évora, Faro, Lisboa, Portalegre, Santarém, Setúbal e Viana do Castelo (polinomial de 3 ordens), pese embora a desigual percentagem de área ardida em GIF, podémos identificar, para este conjunto de distritos, 3 fases de evolução. De uma forma geral, a década de 80 é coincidente com um nítido decréscimo da área ardida, seguindo-se, uma fase de acréscimo, compreendida entre o final dos anos 80 e o início da década de 90 , sendo que o intervalo de anos entre 2003 a 2005 regista os valores mais elevados de área ardida. Finalmente, após este intervalo, parece delinear-se uma expressiva tendência de decréscimo até aos últimos anos analisados (fig. 1).

No caso dos distritos de Aveiro e Leiria, verificou-se uma evolução semelhante, igualmente com uma diminuição da área ardida no início dos anos 80 , e um acréscimo nos anos seguintes, muito embora, neste caso, tanto a tendência de diminuição como a de aumento não tivessem sido tão vincadas como aconteceu nos outros distritos referidos. Aliás, observa-se mesmo uma aparente manutenção da linha de tendência durante as últimas duas décadas, com oscilações pouco significativas. É interessante notar ainda que, no conjunto destes distritos, embora seja evidente a fase final de decréscimo na evolução das áreas ardidas em GIF, o período de tempo em que se dá esta inversão, é ainda relativamente curto para afirmar que esta se irá manter, uma vez que pode resultar de circunstâncias conjunturais.

Já no distrito de Viseu, foi possivel identificar uma tendência completamente oposta à anterior, ou seja, a década de 80 registou um acréscimo da evolução das áreas ardidas, com uma ligeira e gradual diminuição, a partir do início dos anos 90, e que se manteve até 2003, ano, a partir do qual, a tendência foi de novo de aumento. Nos últimos anos analisados, a linha de tendência tornou-se mais expressiva, no que ao aumento da evolução das áreas ardidas, no distrito, se refere (fig. 2).

Os distritos do Porto e Vila Real apresentaram uma tendência de acréscimo progressivo, ao longo do intervalo de anos analisado, que começa de forma expressiva, a partir do final da década de 80 , com uma relativa manutenção dos valores de área ardida nos últimos 3 anos. 



Fig. 1 - Evolução anual da \% de território percorrido por GIF em nove distritos, entre 1981 e 2013, relativamente à sua superficie de espaços silvestres, e respetiva linha de tendência/regressão, traduzida em três fases: decréscimo-aumento-diminuiçao.

Também Braga e Bragança apresentaram uma evolução positiva, com um aumento progressivo da área ardida em GIF ao longo dos últimos 33 anos, assumindo estes distritos uma expressão exponencial.

Pelo contrário, Guarda e Coimbra apresentaram uma tendência de decréscimo das áreas ardidas em GIF. No caso da Guarda, a tendência de decréscimo, ficou a dever-se, sobretudo, às menores percentagens de área ardida assinaladas a partir do início do século XXI. Em contrapartida, Coimbra é o único distrito a delinear uma tendência claramente negativa no periodo de $1981 \mathrm{a}$ 2013, no que à àrea ardida em GIF se refere. 

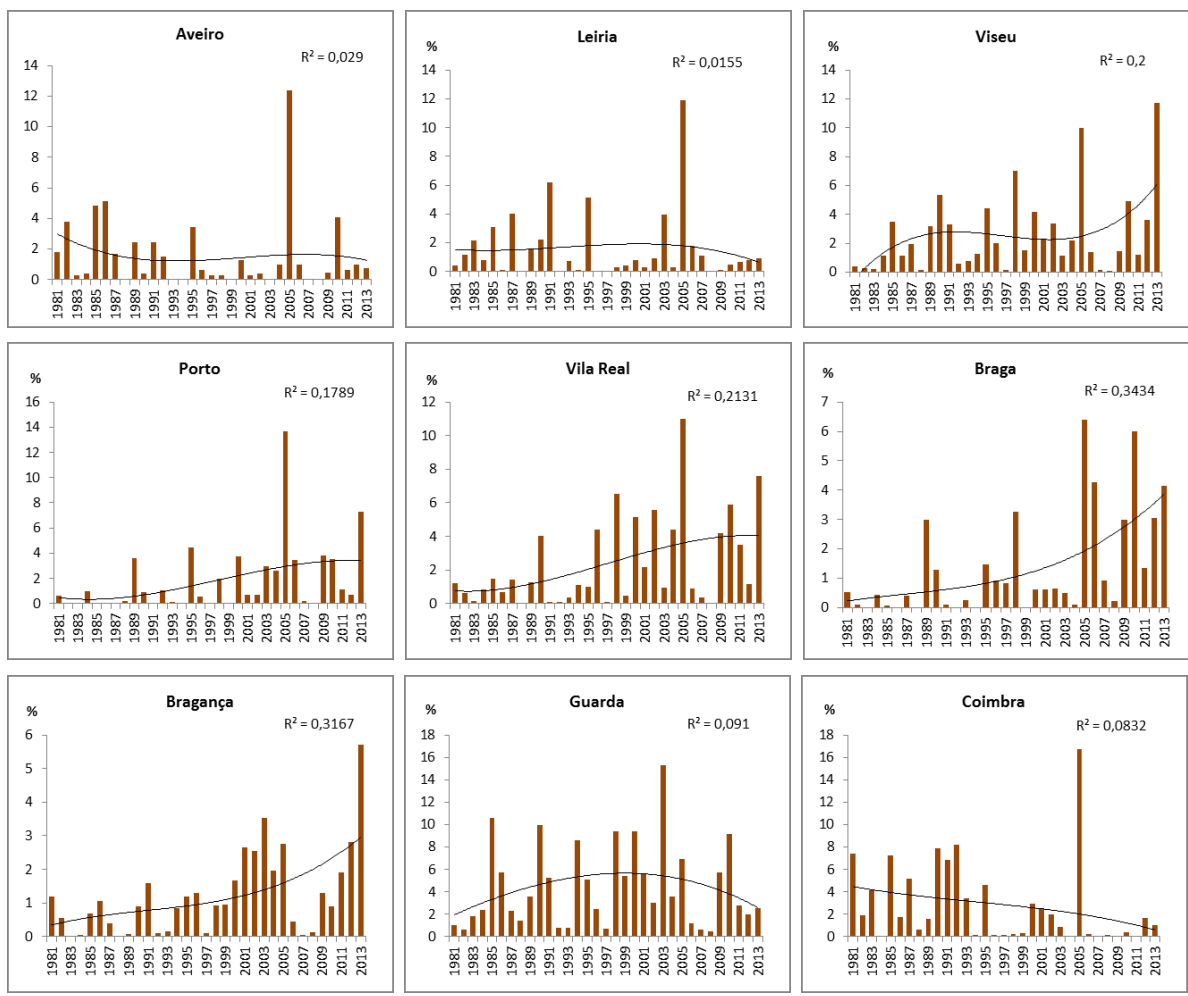

Fig. 2 - Evolução anual da \% de território percorrido por GIF nos restantes nove distritos, entre 1981 e 2013 , relativamente à sua superficie de espaços silvestres, e respetiva linha de tendência/regressão.

\section{Conclusão}

Através da análise da configuração que as linhas de tendência foram adquirindo, para os diferentes distritos, podemos denotar desde logo, o carácter aleatório das áreas ardidas por GIF em Portugal. A confirmá-lo está o facto de que para todos os distritos a linha de tendência que mais se ajustou à distribuição espácio-temporal da informação, ou seja, aquela em que $\mathrm{R}^{2}$ mais se aproxima de 1 , foi a linha de tendência polinomial.

As configurações adquiridas pelas linhas de tendência dos diferentes distritos variam, no entanto, de forma significativa, sendo possível agrupar distritos com maior similaridade em termos de tendência de evolução, pesem embora as desiguais percentagens de área ardida.

Assim, merecem destaque as tendências de aumento nítido evidenciadas pelos distritos de Viseu, Porto, Vila Real, Braga e Bragança, que em muito se ficaram a dever ao aumento da percentagem da área ardida nos últimos anos. Em contrapartida, os restantes distritos apresentam menores percentagens de área ardida nos últimos anos, o que se reflete numa tendência de decréscimo. Neste último conjunto, destaca-se o distrito de Coimbra que foi o único a delinear uma tendência claramente negativa ao longo do período 1981-2013.

Este tipo de análise é interessante na medida em que nos permite questionar sobre os diferentes comportamentos dos distritos, de forma a perceber se, por exemplo, as tendências negativas se 
devem a medidas preventivas postas em prática, ou se essa tendência é mais resultado de muitos e grandes incêndios ocorridos no início do período estudado.

\section{Bibliografia}

Bento-Gonçalves, A. (2006) - Geografia dos incêndios em espaços silvestres de montanha - O caso da Serra da Cabreira, Tese de Doutoramento, Universidade do Minho, 439 p.

Bento-Gonçalves, A.; Vieira, A.; Martins, C.; Ferreira-Leite, F. e Costa, F. (2010) - A desestruturação do mundo rural e o uso do fogo - o caso da serra da Cabreira (Vieira do Minho). In Caminhos nas Ciências Sociais. Memória, Mudança Social e Razão - Estudos em Homenagem a Manuel da Silva Costa. Universidade do Minho, Braga, p. 87-104.

Ferreira-Leite, F.; Bento-Gonçalves, A.; Lourenço, L.; Ùbeda, X. e Vieira, A. (2013) - Grandes incêndios florestais em Portugal Continental como resultado das perturbações nos regimes de fogo no mundo mediterrâneo. Silva Lusitana, n. ${ }^{\circ}$ Especial 1 - 9, p. 129-144.

Ferreira-Leite, F.; Bento-Gonçalves, A. e Lourenço, L (no prelo) - Os grandes incêndios florestais em Portugal breve caracterização. Méditerranée, Presses Universitaires de Provence.

Lourenço, L. (1988) 口 Tipos de tempo correspondentes aos grandes incêndios florestais ocorridos em 1986 no Centro de Portugal. Finisterra, n. ${ }^{\circ} 32$, Lisboa, p. 251-270.

Lourenço, L. e Bento-Gonçalves, A (1990) - As situações meteorológicas e a eclosão-propagação dos grandes incêndios florestais registados durante 1989 no Centro de Portugal. In I/ Congresso Florestal Nacional, Porto, Portugal, p. 755-763.

Lourenço, L.; Bento-Gonçalves, A.; Vieira, A.; Nunes, A. e Ferreira-Leite, F. (2012) - Forest Fires in Portugal, In Bento-Gonçalves, A.; Vieira, A. (Eds.) - Portugal: Economic, Political and Social Issues, Hauppauge, New York, Nova Science Publishers, p. 97-111.

Moreira, F.; Viedma, O.; Arianoutsou, M.; Curt, T.; Koutsias, N.; Rigolot, E.; Barbati, A.; Corona, P.; Vaz, P.; Xanthopoulos, G.; Mouillot, F e Bilgili, E. (2011) - Landscape - wildfire interactions. In Southern Europe: Implications for landscape Management. Journal of Environmental Management, n. ${ }^{\circ} 92, \mathrm{p}$. 2389-2402.

Nunes, A. (2012) - Regional variability and driving forces behind forest fires in Portugal, an overview of the last three decades (1980-2009). Applied Geography, n. ${ }^{\circ} 34$, p. 576-586.

Nunes, A.; Lourenço, L.; Bento-Gonçalves, A. e Vieira, A. (2013) - Três décadas de incêndios florestais em Portugal: incidência espacial e principais fatores responsáveis. Cadernos de Geografia, n. ${ }^{\circ}$ 32, Faculdade de Letras, Coimbra, p. 133-143. 